\title{
Nucleosome-Dependent Pathways That Control Mitotic Progression
}

\author{
Hironori Funabiki, Christopher Jenness, and Christian Zierhut \\ Laboratory of Chromosome and Cell Biology, The Rockefeller University, New York, New York 10065 \\ Correspondence: funabih@rockefeller.edu
}

\begin{abstract}
The majority of eukaryotic chromosomal DNA exists in the form of nucleosomes, where 147 bp DNA wraps around histone hetero-octamers, composed of histone H3, H4, H2A, and H2B. Despite their obvious importance in DNA compaction and accessibility, studying their specific roles, such as regulation of mitotic progression, in a physiological environment is associated with critical caveats because of their major contributions in transcriptional control. Through establishing a method to deplete endogenous histones $\mathrm{H} 3$ and $\mathrm{H} 4$ from frog egg extracts and complementing their functions using recombinant nucleosome arrays, we are now able to analyze their roles in mitotic progression without affecting overall transcriptomic profiles. Here we summarize advancements learned from this system, illustrating that microtubule and nuclear envelope assembly can be regulated by two major nucleosome-bound protein complexes, RCC1-Ran and the chromosomal passenger complex (CPC) containing the mitotic protein kinase Aurora B. We also discuss roles of the CPC on the proteomic composition of mitotic chromatin. The $\mathrm{CPC}$ promotes dissociation of a variety of nucleosome remodelers and DNA repair pathway proteins, suggesting its role in suppressing DNA processing activities on mitotic chromosomes. We speculate that this suppression particularly on chromosomes under microtubule tension may be important to preserve genome integrity.
\end{abstract}

Major characteristics that define eukaryotes are the intracellular membrane system, which forms the nucleus to encapsulate genomic DNA, and cell division through mitosis, where replicated genomic DNA is organized into topologically distinct multiple chromosomal threads, which are distributed equally to two daughter cells. DNA replication and chromosome segregation in eukaryotes rely on formation of microscopic-scale architectures around chromosomes, the nuclear envelope, and spindle microtubules, respectively. Pioneering studies in Xenopus eggs and their extracts have shown that exposure of DNA to cytoplasm can trigger formation of the nuclear envelope in interphase and spindle microtubule assembly in $\mathrm{M}$ phase, in a DNA sequence-independent manner (Forbes et al. 1983; Karsenti et al. 1984; Heald et al. 1996). Here we will review our current understanding of how these DNAinduced processes are controlled by nucleosomes, the fundamental unit that folds genomic DNAs in eukaryotes.

\section{A SYSTEM TO DIRECTLY MANIPULATE HISTONES H3 AND H4 IN XENOPUS EGG EXTRACTS}

DNA added to Xenopus egg extracts is rapidly chromatinized with the large excess of maternally stored histones in egg cytoplasm. To study the roles of nucleosomes, we therefore established a method to deplete histones H3 and H4 from egg extracts and complement them with recombinant proteins (Fig. 1; Zierhut et al. 2014). We used monoclonal antibodies against histone $\mathrm{H} 4$ acetylated at Lys12 (H4K12ac) to deplete the H3-H4 complex, and depleted extracts were complemented with synthetic DNA preassembled with nucleosomes (Fig. 1A,B; Zierhut et al. 2014). As the great majority of histone $\mathrm{H} 4$ in eggs is acetylated at Lys5 and Lys 12 and forms a complex with H3 (Nicklay et al. 2009), monoclonal antibodies against H4K12ac were able to deplete $>90 \%$ of histones H3 and H4. Under this experimental condition, reconstituted nucleosome arrays, coupled to magnetic beads, supported spindle assembly in $\mathrm{M}$ phase extracts and nuclear envelope formation with nuclear import activity in interphase extracts (Fig. 1C; Zierhut et al. 2014). Naked DNA beads in interphase $\Delta \mathrm{H} 3-\mathrm{H} 4$ extracts were able to recruit membranes but were defective in recruiting the nuclear pore complex (NPC). Naked DNA-beads also failed to induce spindle microtubule assembly in $\mathrm{M}$ phase $\Delta \mathrm{H} 3-\mathrm{H} 4$ extracts. These experiments directly showed the importance of nucleosomes in spindle formation and NPC. An independent study in mouse oocyte, where de novo formation of nucleosomes on sperm nuclei can be inhibited by depleting H3.3 or HIRA, also showed the importance of nucleosome formation for NPC assembly (Inoue and Zhang 2014).

\section{MASS SPECTROMETRY ANALYSIS OF NUCLEOSOME-DEPENDENT BINDING PROTEINS}

$\Delta \mathrm{H} 3-\mathrm{H} 4$ egg extracts offered a unique opportunity to compare protein constituents that assemble on nucleosomes and nucleosome-free DNA under physiological conditions using quantitative mass spectrometry (MS)

(C) 2017 Funabiki et al. This article is distributed under the terms of the Creative Commons Attribution-NonCommercial License, which permits reuse and redistribution, except for commercial purposes, provided that the original author and source are credited. 

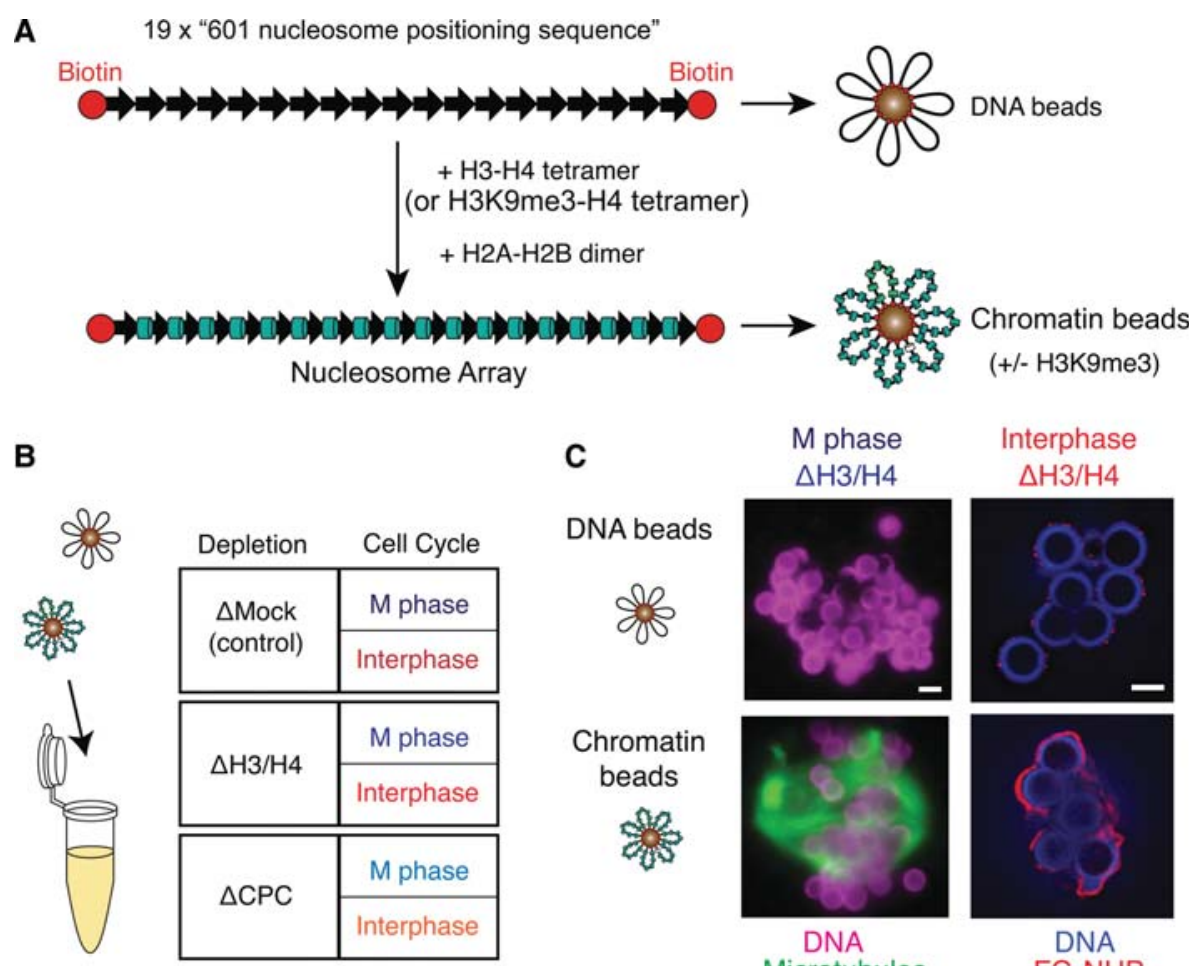

Interphase $\triangle \mathrm{H} 3 / \mathrm{H} 4$
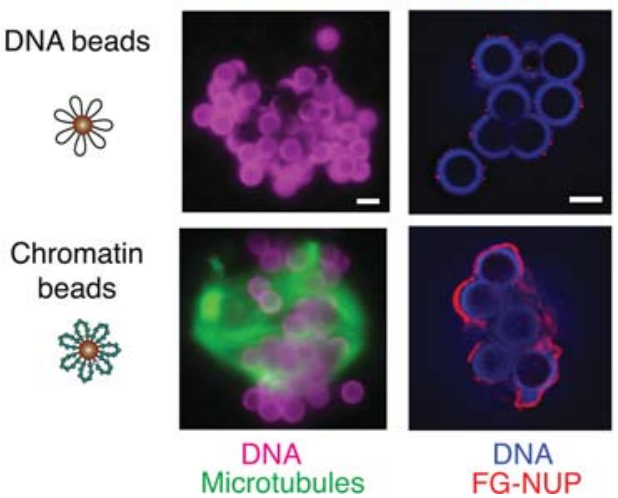

Figure 1. Xenopus egg extract system to determine functions of the nucleosome and specific histone modifications. $(A)$ End-biotinylated tandem 19-mer arrays of Widom's 601 sequences were coupled to streptavidin-coated magnetic beads, with or without nucleosome assembly by salt dialysis using recombinant core histones. (B) Xenopus egg extract conditions. $(C)$ Spindle formation in $M$ phase and nuclear pore complex (NPC) assembly in interphase on DNA/chromatin beads in the absence of histones $\mathrm{H} 3 / \mathrm{H} 4$ were visualized by rhodamine-tubulin and antibodies against the NPC component ELYS. Scale bars, $3 \mu$ m. (Modified from Zierhut et al. 2014; Zierhut and Funabiki 2015.)

analysis. In both $\mathrm{M}$ phase and interphase extracts, the list of most abundant nucleosome-dependent binders are similar; the linker histone H1M, the FACT complex, Ran-RCC1, DDB1, and the chromosomal passenger complex (CPC) (Zierhut et al. 2014; C Jenness and H Funabiki, unpubl.). Unlike the linker histone and potential nucleosome regulators, FACT and DDB1 (Belotserkovskaya and Reinberg 2004; He et al. 2006; Winkler and Luger 2011), RCC1Ran and the CPC play critical roles beyond structural organization of mitotic chromatin, as discussed below.

Intriguingly, SMC-family protein complexes, condensin and cohesin, show a mild preference for nucleosomefree DNA over nucleosomal DNA (Zierhut et al. 2014; Hirano 2016; C Jenness and H Funabiki, unpubl.). This may reflect the evolutionary conservation of SMC proteins in prokaryotes, which lack nucleosomes. Similarly, the MCM complex, the AAA family ATPase required for DNA replication initiation, effectively binds to nucleosomal and nucleosome-free DNA (Zierhut et al. 2014; C Jenness and H Funabiki, unpubl.), although it is not clear at present if this reflects functional, topological, binding. It seems that these protein complexes evolved to acquire additional modules/factors to interact and deal with nucleosomal DNA, such as FACT (Kinoshita et al. 2015; Shintomi et al. 2015; Hirano 2016; Kurat et al. 2017). In contrast, major critical roles in eukaryote-specific events, nuclear envelope formation, and spindle microtubule as- sembly are performed by nucleosome-dependent chromatin proteins, $\mathrm{RCC} 1-\mathrm{Ran}$ and the $\mathrm{CPC}$.

\section{THE RCC1-Ran PATHWAY}

The GTP-bound form of the small GTPase Ran controls a number of processes by modulating karyopherin family proteins, such as importins and exportins (Cavazza and Vernos 2015). RanGTP disrupts the interaction between importin $\beta$ and importin $\alpha$, which recognize a variety of nuclear proteins that contain classical nuclear localization signals (Fig. 2, steps a and b). In the context of nuclear envelope formation, RanGTP liberates components of NPCs from importins (Walther et al. 2003), whereas in M phase, it releases proteins that promote spindle assembly (Cavazza and Vernos 2015). One of many mechanisms involve TPX2, which promotes microtubule nucleation by tethering tubulin dimers and by activating Aurora A and the $\gamma$-tubulin ring complex ( $\gamma$ TuRC) (Fig. 2, step c; Groen et al. 2004; Tsai and Zheng 2005; Pinyol et al. 2013; Roostalu et al. 2015; Scrofani et al. 2015; Zhang et al. 2017).

GDP bound to Ran is exchanged with GTP with the help of RCC1 associated with nucleosomes (Fig. 2, step a; Nemergut et al. 2001; Makde et al. 2010). Although RCC1 can directly interact with DNA, an additional interaction with the acidic patch of $\mathrm{H} 2 \mathrm{~A}-\mathrm{H} 2 \mathrm{~B}$ in the nucleosome is critical 


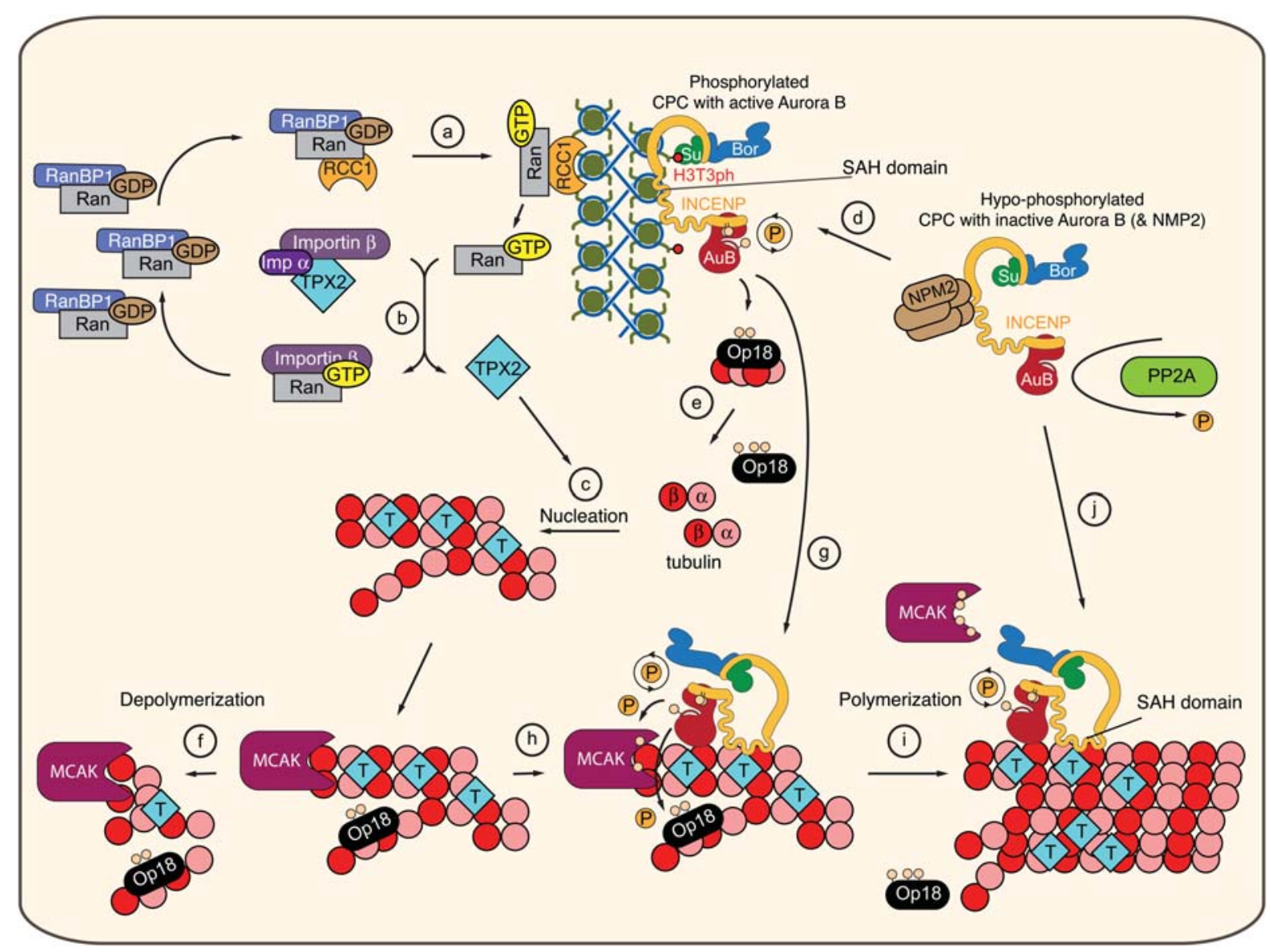

Figure 2. Schematics of chromatin-induced microtubule nucleation. In the cytoplasm distal to chromatin, RanGDP forms a trimeric complex with RCC1 and RanBP1 and is targeted to chromatin via RCC1-nucleosome interaction (step a). On chromatin, GDP is replaced with GTP by RCC1, whose activity is stimulated by nucleosome binding. RanGTP releases a number of proteins, such as TPX2 and other proteins promoting microtubule assembly, from Importins (step b). TPX2 binds and stabilizes interfaces between adjacent $\alpha / \beta$ tubulin dimers to promote microtubule nucleation (step c). In the cytoplasm distal to chromosomes, the chromosomal passenger complex (CPC; composed of Aurora B, INCENP, Borealin, and Survivin) is kept in hypophosphorylated status by PP2A and is bound to NPM2 oligomers. Upon binding to chromatin through Survivin-H3T3ph interaction and the SAH-chromatin interaction, Aurora B and INCENP become phosphorylated, leading to Aurora B activation (step d). Activated Aurora B phosphorylates Op18, which sequesters tubulin dimers. Aurora B-dependent Op18 phosphorylation releases tubulins to promote microtubule assembly (step e). Hypophosphorylated MCAK and Op18 interact with microtubule ends and stimulate depolymerization (step f). The CPC interacts with microtubules through the SAH domain of INCENP. Upon interaction with microtubules, Aurora B is activated (step g). MCAK and Op18 are phosphorylated by Aurora B (step h). Phosphorylated MCAK and Op18 are inactivated, leading to microtubule polymerization (step i). The CPC can directly bind to microtubules and become activated (step j). (Modified from Zierhut and Funabiki 2015; Wheelock et al. 2017.)

(Makde et al. 2010). Ran has been shown to directly interact with histones $\mathrm{H} 3-\mathrm{H} 4$, but this interaction is very weak, and accordingly, our quantitative MS analysis shows that equivalent amount of Ran and RCC1 exist on mitotic chromatin (Bilbao-Cortés et al. 2002; Zierhut et al. 2014; Jenness et al. 2018), even though the concentration of Ran $(5 \mu \mathrm{M})$ in egg cytoplasm is more than 30 -fold higher than that of RCC1 (150 nM) (Wuhr et al. 2015)

A bead coupled directly with RCC1 proteins can promote bipolar spindle assembly, suggesting that local enrichment of $\mathrm{RCC} 1$ can act as an effective trigger for microtubule nucleation and subsequent spindle assembly (Halpin et al. 2011). However, spindles are shorter and spindle microtubule density is lower on an RCC1 bead than on a chromatin bead. This may reflect the involvement of RCC1-independent regulation (e.g., through activation of the $\mathrm{CPC}$, see below) or the presence of additional mechanisms by which chromatin activates RCC1. Indeed, the catalytic activity of RCC 1 is stimulated by nucleosome interaction (Nemergut et al. 2001). Furthermore, RanBP1, whose concentration in eggs is $2 \mu \mathrm{M}$, forms a trimeric complex with Ran and RCC1 to inhibit the catalytic activity of RCC1 (Zhang et al. 2014). Despite its abundance, no RanBP1 was detected on purified chromatin (Zierhut et al. 2014; Jenness et al. 2018), indicating that binding of RCC1-RanGDP-RanBP1 to chromatin releases RanBP1, and thus licenses RanGDP for conversion to RanGTP. It would be interesting to know if RanBP1 is defective in binding to RCC1 that is coupled to beads.

Adding a Ran mutant defective in GTP hydrolysis to egg extracts is sufficient to drive microtubule nucleation and assembly, highlighting the importance of local enrichment of RanGTP (Cavazza and Vernos 2015). However, the dominant negative RanT24N mutant, which inhibits 
RCC1's nucleotide exchange activity, inhibits spindle formation in commonly used Xenopus laevis egg extracts, but not in egg extracts of Xenopus tropicalis (Helmke and Heald 2014). This was attributed to the higher concentration of TPX2 in X. tropicalis eggs than in X. laevis eggs, which was itself thought to cause $X$. tropicalis spindles to be shorter. Therefore, there must be an additional mechanism that restricts microtubule assembly on chromatin. As described below, our laboratory has shown that the CPC, which directly interacts with nucleosomes (Kelly et al. 2010), also contributes to the mechanism by which chromatin locally restricts microtubule assembly.

At the transition from $M$ phase to interphase, RanGTP acquires another function and drives NPC formation in the reassembling nuclear envelope (Fig. 3). RanGTP promotes NPC assembly through liberating components of the NPC, such as those of the NUP107 complex, and excess RanGTP promotes NPC formation in chromatinfree membrane structures, annulate lamellae (Walther et al. 2003). However, RCC1 does not appear to be the sole essential protein that needs to be targeted to chromatin. We showed that ELYS, which links to the NUP107 complex, is recruited to chromatin through directly interacting with histone $\mathrm{H} 2 \mathrm{~A}$ and $\mathrm{H} 2 \mathrm{~B}$ and supports nucleosomedependent NPC formation (Zierhut et al. 2014). Thus, for both spindle assembly and NPC assembly, RCC1 and additional nucleosome-binding proteins are required.

\section{THE CPC IN SPINDLE ASSEMBLY}

Before the realization of RanGTP's importance in spindle assembly, Karsenti and colleagues showed that phosphorylation of Op18 (also known as Stathmin), a regulator of microtubule dynamics, is induced by chromatin in $\mathrm{M}$ phase Xenopus egg extracts (Andersen et al. 1997). Op18 promotes microtubule destabilization by two distinct mechanisms: sequestration of tubulin dimers to reduce the effective concentration of tubulins and binding to curved microtubule protofilaments (Fig. 2, steps e and f; Cassimeris 2002; Gupta et al. 2013). This Op18-mediated destabilization is suppressed by phosphorylation (Cassimeris 2002). Although two of the mitotic phosphorylation sites are Cdk1 targets, Aurora B mediates chromatin-induced phosphorylation at a third site (Ser16 in Xenopus) (Gadea and Ruderman 2006; Kelly et al. 2007).

Aurora B is the kinase subunit of the CPC, which also contains INCENP, Borealin (also known as Dasra, CDCA8), and Survivin (Fig. 2; Carmena et al. 2012). CPC depletion from Xenopus egg extracts or addition of the Aurora B inhibitor ZM447439 inhibits spindle formation (Sampath et al. 2004; Gadea and Ruderman 2005). In addition to Op18, Aurora B also phosphorylates the major microtubule depolymerizing enzyme, MCAK (also known as XKCM1, KIF2C), and suppresses its microtubule depolymerizing activity and chromosome arm local-

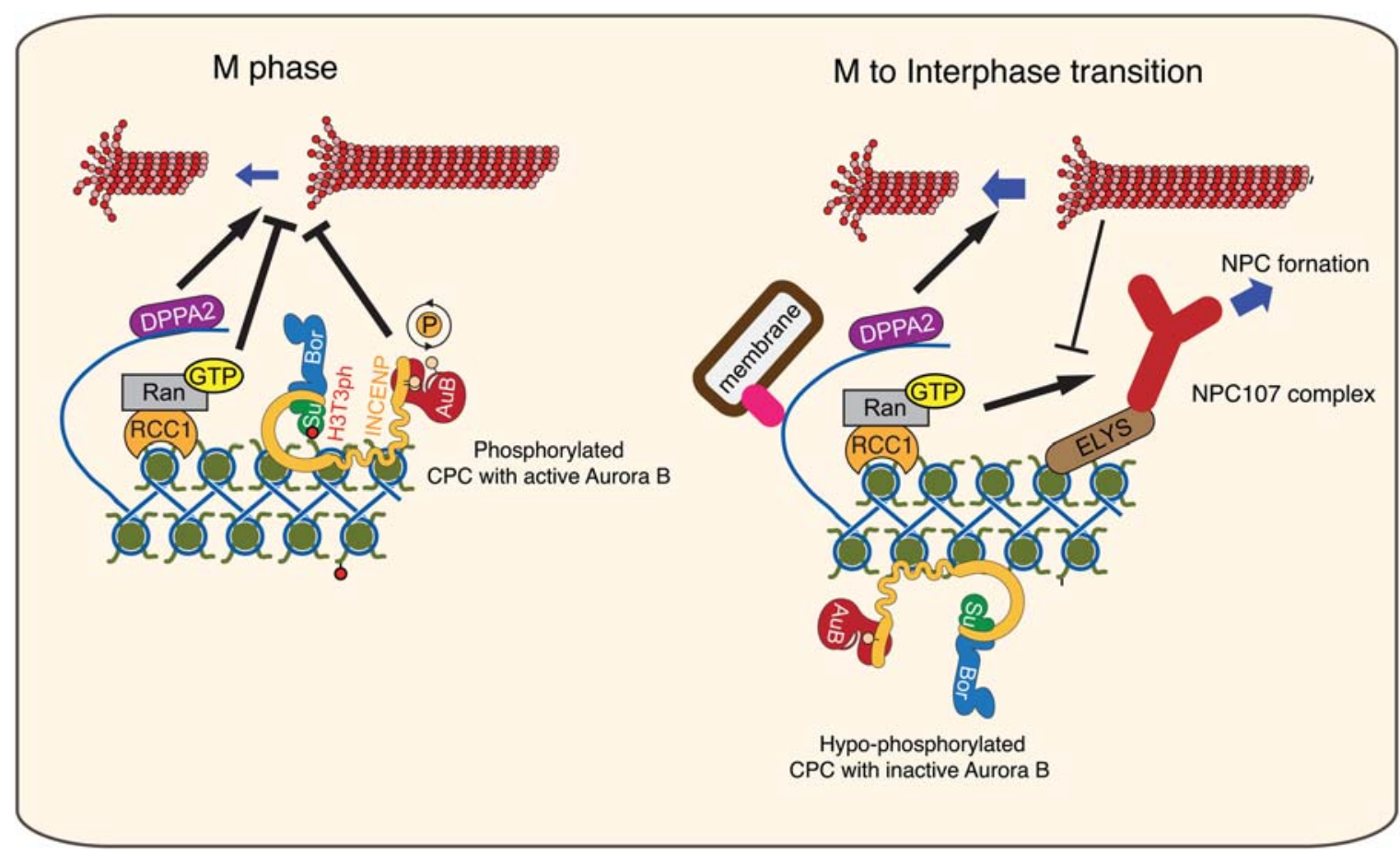

Figure 3. Mechanism of nucleosome-dependent nuclear envelope formation and interference by microtubules. (Left) In M phase, the RanGTP pathway and the chromosomal passenmger complex (CPC) pathways suppress microtubule depolymerization, whereas DNAbinding protein DPPA2 promotes it. (Right) At the transition into interphase, H3T3 is dephosphorylated, resulting in suppression of Aurora B on chromatin. Microtubules inhibit functional nuclear envelope assembly, but DPPA2-mediated microtubule disassembly facilitates nuclear envelope formation. Nuclear membrane can associate nucleosome-free DNA, whereas NPC formation is supported by at least two nucleosome-dependent mechanisms. First, RanGTP liberates building blocks of nuclear pore complex (NPC) microtubule assembly, such as subunits of the NPC107 complex. Second, specifically during interphase, ELYS, which interacts with the NPC107 complex, is recruited to nucleosomes. (Modified from Zierhut and Funabiki 2015; Wheelock et al. 2017.) 
ization (Andrews et al. 2004; Lan et al. 2004; Ohi et al. 2004; Zhang et al. 2007) (Fig. 2, step i; also see Table 2).

The kinase activity of Aurora B is regulated in multiple steps. By itself, Aurora B is a poor protein kinase, but binding of the carboxy-terminal IN-Box module of INCENP allosterically stimulates Aurora B (Bishop and Schumacher 2002; Honda et al. 2003; Sessa et al. 2005). However, binding of INCENP to Aurora B is insufficient to promote effective phosphorylation in egg extracts, where the majority of Aurora B exists in the complex with INCENP along with Dasra A (egg form of Borealin family protein) and Survivin (Bolton et al. 2002; Sampath et al. 2004; Kelly et al. 2007). For full activation of Aurora B, phosphorylation at its catalytic loop (T-loop) and IN-Box must be phosphorylated by Aurora B, but those sites are generally not phosphorylated in egg extracts because of active type 2A (and also likely type 1) phosphatases (Kelly et al. 2007). Nucleoplasmin/nucleophosmin (NPM2) proteins also interact with unphosphorylated, cytoplasmic $\mathrm{CPC}$, although its functional significance remains to be tested (Hanley et al. 2017). However, Aurora B autophosphorylation (a hallmark of kinase activation) can be induced by chromatin or taxol (a microtubule stabilizing drug) in M phase egg extracts (Fig. 2, steps d and j; Kelly et al. 2010; Tseng et al. 2010). Because adding antibodies that cluster the CPC can also promote Aurora B activation, we have proposed that local enrichment of the CPC can activate Aurora B (Kelly et al. 2007). Thus, Aurora B activity can be coupled to intracellular localization.

How can the CPC be recruited to chromatin? We and others showed that Survivin, a CPC subunit important for chromatin targeting (Carvalho et al. 2003; Lens et al. 2003; Yue et al. 2008), directly interacts with the H3 tail when phosphorylated at threonine 3 (H3T3ph) (Fig. 2, step d; Kelly et al. 2010; Wang et al. 2010; Yamagishi et al. 2010). The H3 amino-terminal tail binds to a cleft of the BIR domain of Survivin, in a coordination similar to how the BIR domain of XIAP interacts with SMAC (DIABLO) and caspase-9 (Kelly et al. 2010; Jeyaprakash et al. 2011; Du et al. 2012; Niedzialkowska et al. 2012). In egg extracts, we showed that H3T3ph is critical for chromatin-induced activation of Aurora B, as nucleosomes with a phosphorylation-defective H3T3A mutant fail to activate Aurora B, whereas nucleosomes with a phosphomimetic H3T3E mutant bypass the requirement for the H3T3 kinase Haspin (Kelly et al. 2010; Zierhut et al. 2014). Surprisingly, although Aurora B, INCENP, and Dasra A bind to interphase chromatin at a level comparable to mitotic chromatin (Jenness et al. 2018), activated Aurora $\mathrm{B}$ can be seen only on mitotic chromatin and not on interphase chromatin (C Jenness and H Funabiki, unpubl.). This interphase chromatin association may be supported by the single $\alpha$ helix (SAH) domain of INCENP, which also contributes to chromatin binding (Wheelock et al. 2017), but this is not sufficient to activate Aurora B. Thus, beyond the chromatin enrichment, the M phase-specific H3T3phSurvivin interaction activates Aurora B by an additional mechanism, perhaps involving structural reorganization of the CPC on chromatin related to dimerization capacity of Borealin (Bourhis et al. 2009; Bekier et al. 2015).
The requirement for chromatin-induced mechanisms to activate Aurora B for spindle assembly in Xenopus egg extracts can be bypassed by artificial activation of Aurora B through antibody-mediated clustering (Kelly et al. 2007). Adding the CPC clustering anti-INCENP antibody also facilitates assembly of microtubules that are not attached to chromatin. However, Aurora B activation is only sufficient to promote spindle assembly if INCENP interacts with microtubules through the SAH domain (Fig. 2, steps g and j; Tseng et al. 2010). Therefore, the $\mathrm{SAH}-$ microtubule interaction may be required for optimal substrate phosphorylation, whereby the microtubule-binding capacity of the CPC facilitates phosphorylation of substrates on microtubules (Noujaim et al. 2014). It may be worth noting that Aurora Bdependent phosphorylation often weakens microtubulebinding activity of substrates (Cheeseman et al. 2006; Wang et al. 2007; Gestaut et al. 2008; Alushin et al. 2010), and this is related to the fact that Aurora B is a basophilic kinase (Alexander et al. 2011), whereas basic amino acids are often used to recognize negatively charged E hooks of tubulins. Thus, it is possible that the Aurora B substrate-microtubule interaction may limit the substrate accessibility by Aurora B, necessitating the $\mathrm{CPC}-$ microtubule interaction for effective Aurora B substrate recognition.

A microtubule-targeted fluorescence resonance energy transfer (FRET)-based sensor revealed that Aurora Bdependent phosphorylation on microtubule-bound substrates can be broadly observed across the mitotic spindle in human tissue culture cells (Tseng et al. 2010; Tan and Kapoor 2011). Before the metaphase to anaphase transition, higher phosphorylation levels occur near bulk chromosomes than at regions close to poles. However, on metaphase spindles, the gradient of Aurora B-dependent phosphorylation is not obvious unless Aurora B activity is partially inhibited (Tan and Kapoor 2011; Wang et al. 2011). In contrast, during anaphase, a clear gradient of Aurora B-dependent phosphorylation was seen, centering on the spindle midzone, where the CPC is relocalized from chromosomes at the metaphase to anaphase transition (Fuller et al. 2008; Tan and Kapoor 2011). This difference likely reflects the more stable Aurora B enrichment at the anaphase spindle midzone than in preanaphase mitotic stages when the CPC preferentially enriches on the inner centromere over microtubules.

The weakly tuned microtubule-binding property of INCENP during preanaphase is functionally important. Robust microtubule binding by the INCENP SAH domain requires the adjacent phospho-regulatory domain (PRD) (Wheelock et al. 2017). CDK-dependent phosphorylation of the PRD suppresses, but not completely inhibits, microtubule binding. Strikingly, although deleting the SAH domain prevents the CPC from supporting spindle assembly, replacing the SAH domain with alternative microtubule-binding domain from PRC1 or Tau promotes spontaneous microtubule assembly in the absence of chromatin (Tseng et al. 2010). We therefore speculate that feedback activation of Aurora B by assembled microtubules causes chromatin-independent microtubule assem- 
bly, explaining why the SAH-microtubule interaction must be tuned by Cdk1-dependent phosphorylation.

In HeLa cells, where spindle assembly does not require Aurora B activity, this tuned microtubule-binding capacity of INCENP is critical for activation and suppression of the spindle assembly checkpoint (SAC) (Wheelock et al. 2017). We have shown that SAH-microtubule binding is important to support SAC activation in HeLa cells upon taxol treatment, likely through promoting phosphorylation of kinetochore proteins, such as Hec1, and through destabilizing kinetochore-microtubule interactions. When the microtubule-SAH interaction is enhanced by mutating CDK-dependent phosphorylation sites in the PRD to alanines, cells show a difficulty in silencing the SAC even after metaphase plate formation in otherwise untreated cells. Similarly, the microtubule-binding capacity of INCENP, which is under the negative control of CDK1dependent phosphorylation but not centromere targeting of the CPC, is critical for essential functions of the CPC in budding yeast (Campbell and Desai 2013; Fink et al. 2017). In addition, it was proposed that the interaction between the microtubule plus-end tracking protein EB1 and Aurora B mediates microtubule-dependent Aurora B activation and CPC recruitment to the centromere (Banerjee et al. 2014), and this interaction may also contribute to the function of Aurora B in the SAC.

Despite the capacity of chromatin to stimulate RanGTP production and Aurora B activation, which are both thought to stabilize microtubules, no spatial difference in microtubule stability (and instability) can be found across the metaphase spindle in Xenopus egg extracts (Brugués et al. 2012). Based on a series of experiments and mathematical simulations, Needleman and colleagues have proposed that the spindle size and microtubule length distribution can be explained by spatial regulation of microtubule nucleation but not by that of microtubule stabilization. Incorporation of new microtubules is preferred at the center of the spindle, and microtubules are shorter at the poles. This can be explained by enhanced microtubule nucleation at the spindle equator and the transport of the microtubules by motor proteins (Brugués et al. 2012). A chromatin-centered gradient of microtubule nucleation activity can be generated by RanGTP-mediated activation of spindle assembly factors (SAFs) that interact with microtubules (Carazo-Salas et al. 2001; Groen et al. 2004; Cavazza and Vernos 2015; Oh et al. 2016). The Aurora B pathway may also contribute to local microtubule nucleation around chromatin by inhibiting Op18 and MCAK, which can prevent the formation of elongation-competent microtubule plus ends (Wieczorek et al. 2015). Consistent with this idea, it was reported that the Op18-tubulin interaction is suppressed near mitotic chromatin (Niethammer et al. 2004), and that depletion of Haspin, required for chromatin-induced Aurora B activity, decreases spindle size (Kelly et al. 2010). However, unhydrolyzable RanGTP can promote microtubule nucleation in CPC-depleted extracts (Sampath et al. 2004), suggesting that the $\mathrm{CPC}$ is not required in the presence of excess RanGTP. It is likely that RanGTP and Aurora B both act in a cooperative manner to recognize chromatin and promote microtubule assembly, although their importance in providing spatial information of chromatin can be redundant depending on the system. This may explain why depletion of the CPC subunits or Aurora B inactivation in somatic cells and mammalian oocytes may cause chromosome misalignment and spindle morphology defect but usually does not inhibit spindle assembly (Zierhut and Funabiki 2015), whereas the CPC supports kinetochore-induced microtubule nucleation in somatic cells (Tulu et al. 2006) and is absolutely essential for spindle assembly in Xenopus egg extracts (Sampath et al. 2004).

\section{FUNCTIONAL COORDINATION OF MICROTUBULE DYNAMICS AND NUCLEAR ENVELOPE FORMATION BY CHROMATIN FACTORS}

Although the RCC1-Ran pathway promotes both spindle assembly and nuclear envelope formation (Cavazza and Vernos 2015), the CPC acts to promote spindle assembly but inhibits nuclear envelope formation (Fig. 3). The CPC, which is enriched on centromeres during the preanaphase stages of mitosis, is relocalized to the spindle midzone in anaphase. Preventing this process by either inhibition of the p97-Cdc48 pathway or excessive activity of Haspin, which retains H3T3ph and thus Aurora B activity on chromosomes, delays chromosome decompaction and nuclear envelope formation (Ramadan et al. 2007; Kelly et al. 2010). One of the mechanisms by which Aurora B prevents proper nuclear envelope formation is through microtubules. In Xenopus egg extracts, we have shown that a DNA-bound microtubule-destabilizing protein, Dppa2, is required for formation of a sperm pronucleus of proper size and shape (Xue et al. 2013). This function is opposed by the CPC, suggesting that suppression of microtubule-chromosome interaction by chromatin recruitment of Dppa2, as well as concomitant CPC inhibition, is important for proper nuclear assembly. Although artificial microtubule stabilization with taxol recapitulated this effect, suppression of microtubule assembly by nocodazole also delayed kinetics of nuclear expansion, indicating that microtubules play both positive and negative roles in reformation of the nucleus after mitosis, highlighting the importance of spatiotemporal control of microtubule assembly (Xue et al. 2013). The carboxyterminal microtubule-destabilizing domain of Dppa2 is not conserved in mammalian orthologs, and Dppa2 family proteins are not found in fish and birds, indicating that the role of xDppa 2 in microtubule destabilization may not be evolutionarily conserved. However, the inhibitory function of microtubules in nuclear formation appears to be universal for eukaryotes undergoing open mitosis (Lu et al. 2011; Xue and Funabiki 2014).

\section{ROLE OF THE CPC ON THE PROTEOMIC COMPOSITION OF CHROMATIN}

Major chromatin substrates of Aurora B are the Ser10 and Ser28 residues of histone H3 (Hsu et al. 2000; Goto 


\section{NUCLEOSOME FUNCTIONS IN MITOSIS}

et al. 2002), but their molecular functions are largely mysterious. In budding yeast, it was shown that H3S10ph promotes mitotic chromosome compaction through recruiting the histone $\mathrm{H} 4$ deacetylase Hst2 (Wilkins et al. 2014), but it is unclear if this process is conserved in vertebrates. In human cells, it was suggested that the serine/argininerich splicing factors (SRSFs), SRp20 (SFRS3), and ASF/ SF2 (SRFS1), dissociate from mitotic chromosomes by Aurora B-dependent H310 phosphorylation (Loomis et al. 2009). At heterochoromatin, H3S10ph, inhibits bind- ing of chromodomain of HP1 to its adjacent heterochromatin associated modification, trimethylated Lys9 (H3K9me3) (Fischle et al. 2005; Hirota et al. 2005).

To verify these reported phenomena and to seek novel factors whose binding is influenced by Aurora B-dependent phosphorylation, we examined the impact of CPC depletion on the proteomic profile of chromatin-binding proteins in the presence or absence of H3K9me3 (Fig. 4; Tables 1-3; Jenness et al. 2018). Consistent with our previous findings, we found that HP1 exclusively interacts
A

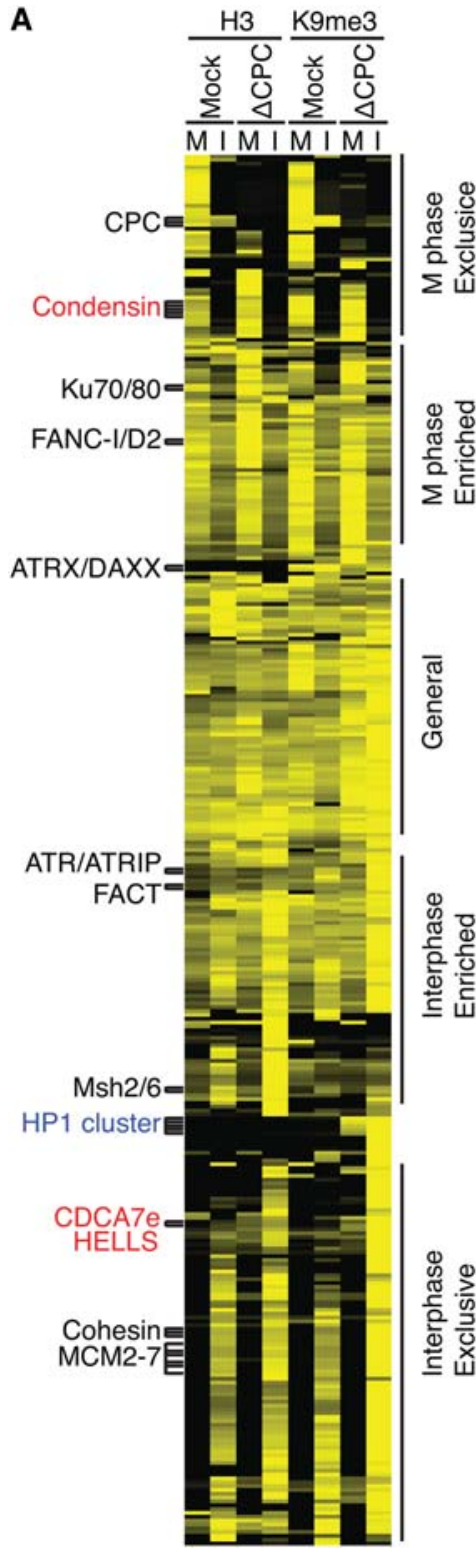

B

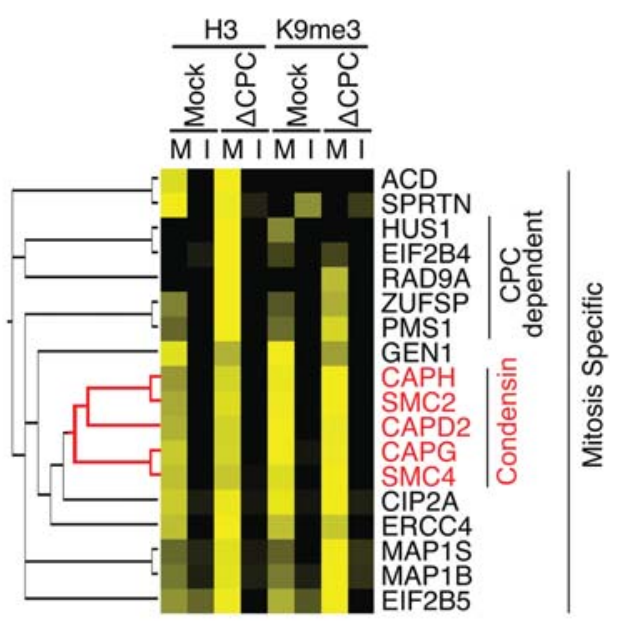

C

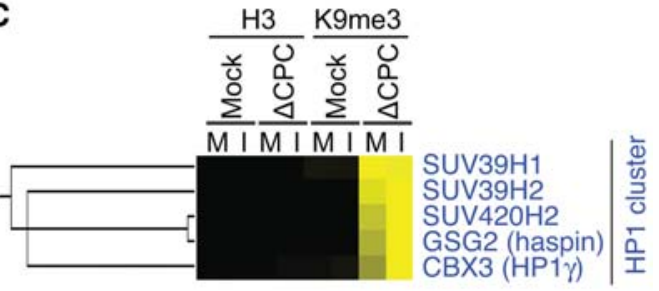

D

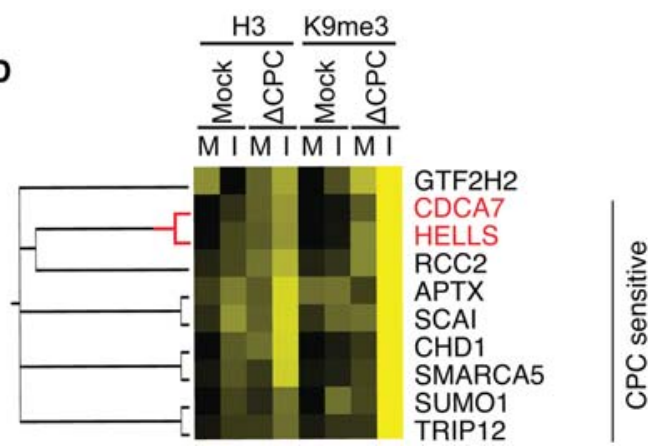

Figure 4. Effect of the chromosomal passenger complex (CPC) depletion, H3K9me3, and cell cycle on the proteomic profile of chromatin. Chromatin beads with or without $\mathrm{H} 3 \mathrm{~K} 9 \mathrm{me} 3$ were incubated with four different egg extract conditions (control $\Delta$ mock extracts or $\triangle \mathrm{CPC}$ extracts in M phase or in interphase) and isolated and then identity and quantity of bound proteins were determined by liquid chromatography-tandem mass chromatography (LC-MS/MS). (A) Based on the similarity of relative abundance across the varying conditions, proteins were clustered using hierarchical clustering algorism. Relative abundance was expressed as a heatmap (low/black to high/yellow). (B) Clades of proteins exclusively enriched on chromatin in M phase, including a few showing CPC dependency. $(C)$ Clades of proteins showing exclusive binding to H3K9me3-nucleosomes in $\triangle$ CPC extracts. $(D)$ Clade of proteins showing reduced binding to $\mathrm{M}$ phase chromatin in a manner dependent on the CPC. (Modified from Jenness et al. 2018.) 
Table 1. Most abundant M phase chromatin-associated proteins in a manner dependent on the chromosomal passenger complex (CPC)

\begin{tabular}{|c|c|c|c|c|c|}
\hline Gene & Alt name & Complex & $\begin{array}{c}\Delta \mathrm{CPC} \text { chromatin } \\
\text { abundance (A.U.) }\end{array}$ & $\Delta$ mock chromatin abundance (A.U.) & $\Delta \mathrm{mock} / \Delta \mathrm{CPC}$ \\
\hline CCNB2 & Cyclin B2 & & 0 & $1.8 \times 10^{8}$ & - \\
\hline CDCA8 & Dasra A, Borealin & $\mathrm{CPC}$ & 0 & $1.7 \times 10^{8}$ & - \\
\hline AURKB & Aurora B & $\mathrm{CPC}$ & 0 & $1.3 \times 10^{8}$ & - \\
\hline ZFP161 & ZBTB14, ZNF478 & & 0 & $1.1 \times 10^{8}$ & - \\
\hline TPX2 & & HURP & $3.0 \times 10^{7}$ & $1.1 \times 10^{8}$ & 3.8 \\
\hline ZMYM4 & ZNF262 & & 0 & $1.1 \times 10^{8}$ & - \\
\hline DLGAP5 & HURP & HURP & $1.7 \times 10^{7}$ & $1.0 \times 10^{8}$ & - \\
\hline PSMB8 & & Proteasome & 0 & $8.7 \times 10^{7}$ & - \\
\hline INCENP & & $\mathrm{CPC}$ & 0 & $8.3 \times 10^{7}$ & - \\
\hline EML4 & EMAP-4 & & 0 & $6.2 \times 10^{7}$ & - \\
\hline EVC & & & 0 & $6.1 \times 10^{7}$ & - \\
\hline TRIM2 & & & 0 & $6.0 \times 10^{7}$ & - \\
\hline RDBP & NELFE & & 0 & $5.9 \times 10^{7}$ & - \\
\hline FAM98B & & & 0 & $5.7 \times 10^{7}$ & - \\
\hline KIFC1 & HSET & & 0 & $4.6 \times 10^{7}$ & - \\
\hline NME2 & NDP-kinase 2 & & 0 & $3.8 \times 10^{7}$ & - \\
\hline BIRC5 & Survivin & $\mathrm{CPC}$ & 0 & $3.8 \times 10^{7}$ & - \\
\hline RPSA & Laminin Receptor 1 & & $1.0 \times 10^{7}$ & $3.7 \times 10^{7}$ & 3.5 \\
\hline CCNB1 & Cyclin B1 & & 0 & $3.1 \times 10^{7}$ & - \\
\hline MAP4 & & & 0 & $3.0 \times 10^{7}$ & - \\
\hline EEF2 & EF2 & & 0 & $3.0 \times 10^{7}$ & - \\
\hline HMMR & RHAMM & RHAMM- $\gamma$ TuRC-TPX2 & 0 & $3.0 \times 10^{7}$ & - \\
\hline
\end{tabular}

Data are generated from Supplemental Table S1 in Jenness et al. 2018.

Abundance (arbitrary units) of proteins that associate with chromatin beads in M phase Xenopus egg extracts in a manner dependent on the CPC are shown. The top 22 most abundant proteins (except for tubulins, actins, mitochondrial proteins, and highly abundant glycolytic enzymes) showing at least threefold enrichment on chromatin in control $\triangle$ mock egg extracts over $\triangle \mathrm{CPC}$ extracts are listed. Subunits of the CPC and the HURP complex are colored in red and blue, respectively. Other known microtubule-binding proteins are shown in purple.

with $\mathrm{H} 3 \mathrm{~K} 9 \mathrm{me} 3$ particular in CPC-depleted $(\triangle \mathrm{CPC})$ extracts (Fig. 4C). Other known H3K9me3-binding proteins containing a chromodomain, Suv39h1, Suv39h2, and Suv420h2, also showed this pattern. In addition, Haspin
(GSG2), whose fission yeast homolog is known to interact with HP1 homolog Swi6 (Yamagishi et al. 2010), showed similar behavior, indicating the evolutionary conservation of HP1-Haspin interaction. In contrast, despite their high

Table 2. Proteins that dissociate from $M$ phase chromatin in a manner dependent on the chromosomal passenger complex (CPC) (I)

\begin{tabular}{|c|c|c|c|c|c|}
\hline Gene & Alt name & Complex & $\begin{array}{c}\Delta \mathrm{CPC} \text { chromatin abundance } \\
\text { (A.U.) }\end{array}$ & $\begin{array}{l}\Delta \text { mock chromatin abundance } \\
\text { (A.U.) }\end{array}$ & $\begin{array}{l}\Delta \mathrm{CPC} / \\
\Delta \mathrm{mock}\end{array}$ \\
\hline CDCA7 & & CHIRRC & $4.6 \times 10^{8}$ & 0 & - \\
\hline HELLS & LSH, SMARCA6 & CHIRRC & $4.6 \times 10^{8}$ & $2.0 \times 10^{7}$ & 22 \\
\hline CHD1 & & & $1.9 \times 10^{8}$ & 0 & - \\
\hline SMARCA5 & SNF2H, ISWI & $\begin{array}{l}\text { ASF/WICH/CHRAC/ } \\
\text { RSF }\end{array}$ & $1.9 \times 10^{8}$ & $5.5 \times 10^{7}$ & 3.3 \\
\hline EIF2B3 & & & $1.6 \times 10^{8}$ & 0 & - \\
\hline BAZ1B & WSTF & WICH & $1.5 \times 10^{8}$ & $4.5 \times 10^{7}$ & 3.3 \\
\hline CCDC39 & & & $1.4 \times 10^{8}$ & 0 & - \\
\hline UBE3C & & & $1.4 \times 10^{8}$ & 0 & - \\
\hline CUL9 & & & $1.3 \times 10^{8}$ & 0 & - \\
\hline PLCH2 & & & $1.1 \times 10^{8}$ & 0 & - \\
\hline $\mathrm{CDH} 23$ & Cadherin-23 & & $9.5 \times 10^{7}$ & 0 & - \\
\hline BAZ1A & $\mathrm{ACF} 1$ & ASF/CHRAC & $7.4 \times 10^{7}$ & 0 & - \\
\hline TRIP12 & & & $6.5 \times 10^{7}$ & $1.8 \times 10^{7}$ & 3.6 \\
\hline MDC1 & & & $6.3 \times 10^{7}$ & $1.8 \times 10^{7}$ & 3.5 \\
\hline ATAD2B & & & $6.3 \times 10^{7}$ & 0 & - \\
\hline DAZAP2 & & & $6.0 \times 10^{7}$ & 0 & - \\
\hline TTN & & & $5.6 \times 10^{7}$ & 0 & - \\
\hline AIM1 & CRYBG1 & & $5.3 \times 10^{7}$ & 0 & - \\
\hline PSMD8 & RPN12 & $26 \mathrm{~S}$ proteasome & $5.2 \times 10^{7}$ & $1.1 \times 10^{7}$ & 4.8 \\
\hline $\mathrm{KIF} 2 \mathrm{C}$ & MCAK, XKCM1 & & $5.0 \times 10^{7}$ & $8.4 \times 10^{6}$ & 5.9 \\
\hline $\mathrm{RCC} 2$ & TD-60 & & $5.0 \times 10^{7}$ & $1.4 \times 10^{7}$ & 3.4 \\
\hline IGF2BP3 & & & $4.8 \times 10^{7}$ & $4.2 \times 10^{6}$ & 11 \\
\hline ATAD2 & & & $4.1 \times 10^{7}$ & 0 & - \\
\hline
\end{tabular}

Data are generated from Supplemental Table S1 in Jenness et al. 2018.

Abundance (arbitrary units) of proteins that associate with chromatin-beads in M phase Xenopus egg extracts preferentially in $\Delta$ CPC extracts are shown. The top 23 most abundant proteins showing at least threefold enrichment on chromatin in $\triangle \mathrm{CPC}$ egg extracts over control $\Delta$ mock extracts are listed. Subunits of the CHIRRC are colored in red. Proteins forming a complex with SMARCA5 are in blue. 
Table 3. Proteins that dissociate from M phase chromatin in a manner dependent on the chromosomal passenger complex (CPC) (II)

\begin{tabular}{lllcc}
\hline & \multicolumn{1}{c}{ Alt name } & \multicolumn{1}{c}{ Complex } & $\Delta$ CPC chromatin abundance (A.U.) & $\Delta$ mock chromatin abundance (A.U.) \\
\hline RAD1 & & 9-1-1 & $3.2 \times 10^{7}$ & 0 \\
SGOL1 & Sgo1 & Shugoshin & $3.1 \times 10^{7}$ & 0 \\
POLE3 & CHRAC17 & CHRAC & $2.9 \times 10^{7}$ & 0 \\
HUS1 & & $9-1-1$ & $2.9 \times 10^{7}$ & 0 \\
FEN1 & & PRP19 & $2.1 \times 10^{7}$ & 0 \\
PRPF19 & & Importin & $2.0 \times 10^{7}$ & 0 \\
KPNA2 & Importin $\alpha$ & MCM & $2.0 \times 10^{7}$ & 0 \\
MCM7 & & TONSL-MMS22L & $2.0 \times 10^{7}$ & 0 \\
MMS2L & & SET & $1.9 \times 10^{7}$ & 0 \\
APEX1 & & $1.9 \times 10^{7}$ & 0 \\
CSNK2A1 & Casein kinase 2 & & $1.9 \times 10^{7}$ & 0 \\
RAD9A & & 9-1-1 & $1.8 \times 10^{7}$ & 0 \\
HIST1H1D & Histone H1.3 & & $1.8 \times 10^{7}$ & 0 \\
THOC2 & & THO & $1.8 \times 10^{7}$ & 0 \\
MCM2 & & MCM & $1.8 \times 10^{7}$ & 0 \\
UHRF1 & & & $1.6 \times 10^{7}$ & 0 \\
TONSL & & TONSL-MMS22L & $1.6 \times 10^{7}$ & $4.5 \times 10^{6}$ \\
RDM1 & RAD52B & & $1.6 \times 10^{7}$ & 0 \\
THOC1 & & THO & $1.5 \times 10^{7}$ & 0 \\
PPP2R5D & PP2A B56Delta & Shugoshin & $1.5 \times 10^{7}$ & 0 \\
RSF1 & & RSF & $1.4 \times 10^{7}$ & 0 \\
MCM3 & & MCM & $1.4 \times 10^{7}$ & 0 \\
PMS2 & & MutL $\alpha$ & $1.1 \times 10^{7}$ & $1.0 \times 10^{7}$ \\
KPNB1 & Importin $\beta$ & Importin & & 0 \\
\hline
\end{tabular}

Data are generated from Supplemental Table S1 in Jenness et al. 2018.

Abundance (arbitrary units) of notable proteins that associate with chromatin-beads in M phase Xenopus egg extracts preferentially in $\Delta \mathrm{CPC}$ extracts are shown. Proteins forming a complex with SMARCA5 are in blue.

abundance in egg extracts (100-1000 nм) (Wuhr et al. 2015), none of the SRSF proteins could be copurified with chromatin at any conditions, even in $\triangle \mathrm{CPC}$ extracts (Jenness et al. 2018). SIRT2 is one of the most abundant known histone deacetylases in Xenopus eggs (178 nм) (Wuhr et al. 2015), but SIRT2 could also not be detected on purified chromatin at any condition including $\mathrm{M}$ phase (Jenness et al. 2018). The only histone deacetylase that could be detected on chromatin was HDAC1, but its chromatin association was restricted to interphase (Jenness et al. 2018). Thus, the proposed interaction between Hst2 and H3S10ph may be too dynamic to detect by our method, limited to anaphase, not conserved in Xenopus egg extracts, or require additional conditions that may not be met on the DNA beads that we used.

Several proteins showed CPC-dependent binding to or dissociation from chromatin beads (Tables 1-3). Many of the CDC-dependent binders were microtubule-binding proteins, likely reflecting the role of the CPC in microtubule assembly (Table 1; Jenness et al. 2018). It remains to be clarified if these interactions depend on microtubules that survived our bead-washing procedures. Although it has been suggested that Aurora B contributes to condensin association with mitotic chromosomes (Tada et al. 2011), CPC depletion did not show any impact on chromatin enrichment of condensin and DNA topoisomerase II in Xenopus egg extracts (Fig. 4B; MacCallum et al. 2002; Jenness et al. 2018). Proteins whose chromatin association is negatively regulated by the CPC include several nucleosome-remodeling complexes such as CHIRRC (HELLSCDCA7), WICH (ISWI-WSTF), CHRAC (ISWI-ACF1POLE3), and RSF (ISWI-RSF1) (Fig. 4D; Tables 2,3; MacCallum et al. 2002; Jenness et al. 2018), but neither
H3S10ph nor H3S28ph contributed to dissociation of HELLS and ISWI from chromatin in M phase (Jenness et al. 2018), indicating that these effects are not mediated through phosphorylation of $\mathrm{H} 3 \mathrm{~S} 10$ or $\mathrm{H} 3 \mathrm{~S} 28$. In addition to nucleosome remodelers, the $\mathrm{CPC}$ also dissociates a variety of proteins involved in DNA repair and replication (Tables 2 and 3). Although future investigations are required to establish the role of H3S10ph and H3S28ph outside the context of $\mathrm{H} 3 \mathrm{~K} 9 \mathrm{me} 3$, these data suggest that the CPC (and perhaps H3S10ph/H3S28ph) contribute to suppressing DNA processing during mitosis.

An intriguing possibility is that local suppression of the CPC pathway enables targeting some of these factors at specific chromosomes or loci (Fig. 5). For example, chromosome arm binding of Sgol and MCAK are suppressed by the CPC (Tables 2,3; Zhang et al. 2007; Rivera et al. 2012), but their centromeric enrichment can be positively regulated by Aurora B (Tanno et al. 2010). A similar mechanism may be relevant when chromosomes undergo missegregation and are lagged behind during anaphase. Aurora B-dependent phosphorylation on chromosome substrates (e.g., H3S10) is maintained on lagging chromosomes even when segregated chromosomes are dephosphorylated (Su et al. 1999; Fuller et al. 2008). As proposed for regulation of nuclear envelope reassembly (Afonso et al. 2014), preventing loading of nucleosome remodelers and other DNA processing proteins to lagging chromosomes may be important to preserve genome integrity, particularly, when these chromosomes are interacting with microtubules (Fig. 5). The pushing and pulling forces generated by a single microtubule fiber are estimated to be $\sim 50$ pN (Nicklas 1983; Jannink et al. 1996; Grishchuk et al. 2005; Bloom 2008). This is comparable to the 

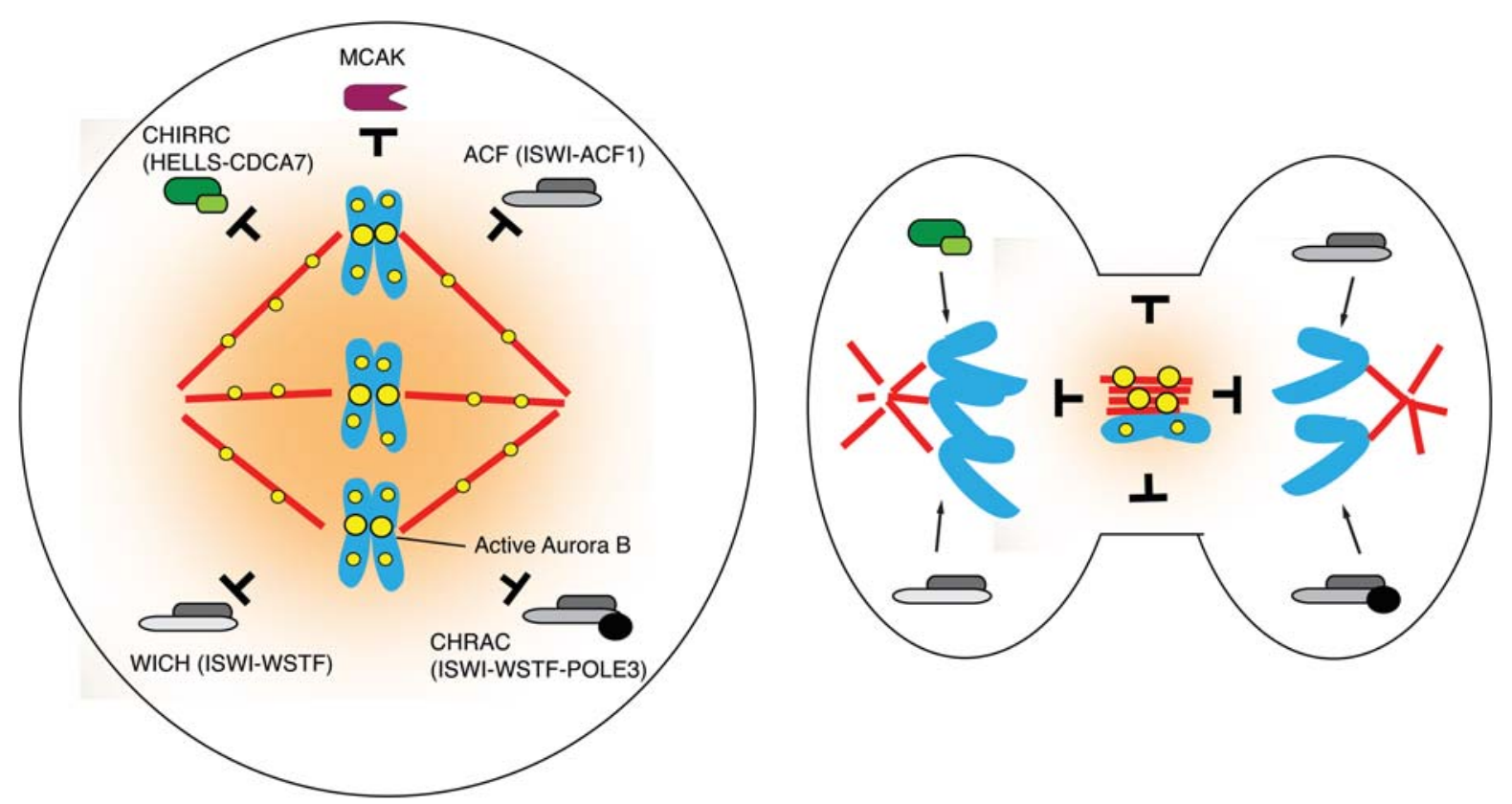

Figure 5. Hypothetical role of Aurora B-dependent removal of mitotic chromatin proteins. During preanaphase stages of mitosis (left), Aurora B activated by chromosomes and/or microtubules promote dissociation of the microtubule-destabilizing protein MCAK and chromatin-remodeling complexes, CHIRRC, ACF, CHRAC, and WICH. In an anaphase/telophase cell with a lagging chromosome associated with spindle midzone (right), Aurora B-dependent phosphorylation is restricted to regions adjacent to the midzone, where reloading of the chromatin remodeling complexes is inhibited.

measured force $(20 \mathrm{pN})$ required to evict nucleosomes from DNA in vitro (Cui and Bustamante 2000; Bloom 2008). In Xenopus interphase egg extracts, as little as $4 \mathrm{pN}$ is sufficient to unwrap nucleosomes in the absence of ATP, and the presence of ATP further destabilizes nucleosomes, making them vulnerable to a force as low as 1 pN (Yan et al. 2007). It would be interesting to explore the possibility that displacement of chromatin remodeling or processing proteins is important to suppress microtubule-dependent alternation of chromatin structure and the formation of DNA damage in lagging chromosomes.

\section{CONCLUSION}

Nucleosomes are critical for microtubule formation during M phase and NPC assembly in interphase. RCC1-Ran and the CPC are key nucleosome-binding components that regulate both of these processes. Although RCC1Ran acts positively for both events, the CPC promotes spindle assembly but suppresses nuclear formation. Many nucleosome-binding factors, such as nucleosomeremodeling proteins and histone chaperones, are used to control DNA accessibility. Unlike these regulators, RCC1-RanGTP and the CPC help to form eukaryote-specific macrostructure assembly through regulating proteins that are not necessarily directly interacting with chromatin. In addition, it has been suggested that RanGTP converts the chromatin-remodeling factor ISWI into a microtubulebinding protein to control anaphase spindle stability (Yokoyama et al. 2009). Therefore, it is plausible that other nucleosome regulators may also have other distinct functions.

Our efforts to understand nucleosome-dependent and -independent processes raise the question of why nuclear envelope formation is broken into steps that can be mediated by nucleosome-free DNA, which can recruit membranes, and steps that require nucleosomes, which are necessary for NPC assembly. We speculate that this mechanism may be actively used to avoid spontaneous formation of functional nuclei from exogenous nucleosome-free DNA, such as that of viruses and other pathogens. An exception is the DNA provided by sperm, where spermspecific protamines tightly pack DNA in a manner that prevents DNA replication and transcription. Thus, fertilization is a unique developmental event where external DNAs that penetrate into the egg cytoplasm rapidly assemble into nucleosomes. This is made possible by prestored soluble histone pools and histone chaperones that support de novo nucleosome assembly. In contrast, invasion of foreign DNA into somatic cells, whose cytoplasm harbors little soluble histones, may trigger innate immune response (Chen et al. 2016). We hypothesized that nucleosome-dependency of spindle assembly and NPC formation allows eukaryotic cells to distinguish between foreign nucleosome-free DNAs, such as those from virus and bacteria, and genomic nucleosomal DNAs, so that foreign DNAs cannot easily hijack the replication and segregation system (Zierhut et al. 2014; Zierhut and Funabiki 2015). We are currently exploring the possibility that nucleosomes could suppress a response by a cytoplasmic DNA sensor involved in innate immune response (Zierhut and Funabiki 2017). It is tempting to speculate that suppres- 
sion of nucleosome remodeling and unwrapping on lagging chromosomes inhibits such sensors that recognize pathogenic or foreign DNA. In this sense, nucleosome loss in mitosis can be sensed as an aberration, and if difficult to be repaired, it may trigger a mechanism to purge these problematic cells.

\section{ACKNOWLEDGMENTS}

The research of H.F. is supported by grants from the National Institutes of Health (R01GM075249 and R01GM125302).

\section{REFERENCES}

Afonso O, Matos I, Pereira AJ, Aguiar P, Lampson MA, Maiato H. 2014. Feedback control of chromosome separation by a midzone Aurora B gradient. Science 345: 332-336.

Alexander J, Lim D, Joughin BA, Hegemann B, Hutchins JR, Ehrenberger T, Ivins F, Sessa F, Hudecz O, Nigg EA, et al. 2011. Spatial exclusivity combined with positive and negative selection of phosphorylation motifs is the basis for contextdependent mitotic signaling. Sci Signal 4: ra42.

Alushin GM, Ramey VH, Pasqualato S, Ball DA, Grigorieff N, Musacchio A, Nogales E. 2010. The Ndc80 kinetochore complex forms oligomeric arrays along microtubules. Nature 467 : 805-810

Andersen SS, Ashford AJ, Tournebize R, Gavet O, Sobel A, Hyman AA, Karsenti E. 1997. Mitotic chromatin regulates phosphorylation of Stathmin/Op18. Nature 389: 640-643.

Andrews PD, Ovechkina Y, Morrice N, Wagenbach M, Duncan K, Wordeman L, Swedlow JR. 2004. Aurora B regulates MCAK at the mitotic centromere. Dev Cell 6: 253-268.

Banerjee B, Kestner CA, Stukenberg PT. 2014. EB1 enables spindle microtubules to regulate centromeric recruitment of Aurora B. J Cell Biol 204: 947-963.

Bekier ME, Mazur T, Rashid MS, Taylor WR. 2015. Borealin dimerization mediates optimal CPC checkpoint function by enhancing localization to centromeres and kinetochores. Nat Commun 6: 6775.

Belotserkovskaya R, Reinberg D. 2004. Facts about FACT and transcript elongation through chromatin. Curr Opin Genet Dev 14: $139-146$.

Bilbao-Cortés D, Hetzer M, Längst G, Becker PB, Mattaj IW. 2002. Ran binds to chromatin by two distinct mechanisms. Curr Biol 12: 1151-1156.

Bishop JD, Schumacher JM. 2002. Phosphorylation of the carboxyl terminus of inner centromere protein (INCENP) by the Aurora B Kinase stimulates Aurora B kinase activity. $J$ Biol Chem 277: 27577-27580.

Bloom KS. 2008. Beyond the code: The mechanical properties of DNA as they relate to mitosis. Chromosoma 117: 103-110.

Bolton MA, Lan W, Powers SE, McCleland ML, Kuang J, Stukenberg PT. 2002. Aurora B kinase exists in a complex with survivin and INCENP and its kinase activity is stimulated by survivin binding and phosphorylation. Mol Biol Cell 13: 3064-3077.

Bourhis E, Lingel A, Phung Q, Fairbrother WJ, Cochran AG. 2009. Phosphorylation of a borealin dimerization domain is required for proper chromosome segregation. Biochemistry 48: 6783-6793.

Brugués J, Nuzzo V, Mazur E, Needleman DJ. 2012. Nucleation and transport organize microtubules in metaphase spindles. Cell 149: 554-564.

Campbell CS, Desai A. 2013. Tension sensing by Aurora B kinase is independent of survivin-based centromere localization. Nature 497: 118-121.

Carazo-Salas RE, Gruss OJ, Mattaj IW, Karsenti E. 2001. RanGTP coordinates regulation of microtubule nucleation and dy- namics during mitotic-spindle assembly. Nat Cell Biol 3: 228 234.

Carmena M, Wheelock M, Funabiki H, Earnshaw WC. 2012. The chromosomal passenger complex (CPC): From easy rider to the godfather of mitosis. Nat Rev Mol Cell Biol 13: 789 803.

Carvalho A, Carmena M, Sambade C, Earnshaw WC, Wheatley SP. 2003. Survivin is required for stable checkpoint activation in taxol-treated HeLa cells. J Cell Sci 116(Pt 14): 2987-2998.

Cassimeris L. 2002. The oncoprotein 18/stathmin family of microtubule destabilizers. Curr Opin Cell Biol 14: 18-24.

Cavazza T, Vernos I. 2015. The RanGTP pathway: From nucleocytoplasmic transport to spindle assembly and beyond. Front Cell Dev Biol 3: 82.

Cheeseman IM, Chappie JS, Wilson-Kubalek EM, Desai A. 2006. The conserved KMN network constitutes the core microtubule-binding site of the kinetochore. Cell 127: 983-997.

Chen Q, Sun L, Chen ZJ. 2016. Regulation and function of the cGAS-STING pathway of cytosolic DNA sensing. Nat Immunol 17: 1142-1149.

Cui Y, Bustamante C. 2000. Pulling a single chromatin fiber reveals the forces that maintain its higher-order structure. Proc Natl Acad Sci 97: 127-132.

Du J, Kelly AE, Funabiki H, Patel DJ. 2012. Structural basis for recognition of H3T3ph and Smac/DIABLO N-terminal peptides by human Survivin. Structure 20: 185-195.

Fink S, Turnbull K, Desai A, Campbell CS. 2017. An engineered minimal chromosomal passenger complex reveals a role for INCENP/Sli15 spindle association in chromosome biorientation. J Cell Biol 216: 911-923.

Fischle W, Tseng BS, Dormann HL, Ueberheide BM, Garcia BA, Shabanowitz J, Hunt DF, Funabiki H, Allis CD. 2005. Regulation of HP1-chromatin binding by histone H3 methylation and phosphorylation. Nature 438: 1116-1122.

Forbes DJ, Kirschner MW, Newport JW. 1983. Spontaneous formation of nucleus-like structures around bacteriophage DNA microinjected into Xenopus eggs. Cell 34: 13-23.

Fuller BG, Lampson MA, Foley EA, Rosasco-Nitcher S, Le KV, Tobelmann P, Brautigan DL, Stukenberg PT, Kapoor TM. 2008. Midzone activation of aurora B in anaphase produces an intracellular phosphorylation gradient. Nature 453: 1132 1136.

Gadea BB, Ruderman JV. 2005. Aurora kinase inhibitor ZM447439 blocks chromosome-induced spindle assembly, the completion of chromosome condensation, and the establishment of the spindle integrity checkpoint in Xenopus egg extracts. Mol Biol Cell 16: 1305-1318.

Gadea BB, Ruderman JV. 2006. Aurora B is required for mitotic chromatin-induced phosphorylation of Op18/Stathmin. Proc Natl Acad Sci 103: 4493-4498.

Gestaut DR, Graczyk B, Cooper J, Widlund PO, Zelter A, Wordeman L, Asbury CL, Davis TN. 2008. Phosphoregulation and depolymerization-driven movement of the Dam1 complex do not require ring formation. Nat Cell Biol 10: 407-414.

Goto H, Yasui Y, Nigg EA, Inagaki M. 2002. Aurora-B phosphorylates Histone $\mathrm{H} 3$ at serine28 with regard to the mitotic chromosome condensation. Genes Cells 7: 11-17.

Grishchuk EL, Molodtsov MI, Ataullakhanov FI, McIntosh JR. 2005. Force production by disassembling microtubules. $\mathrm{Na}$ ture 438: 384-388.

Groen AC, Cameron LA, Coughlin M, Miyamoto DT, Mitchison TJ, Ohi R. 2004. XRHAMM functions in ran-dependent microtubule nucleation and pole formation during anastral spindle assembly. Curr Biol 14: 1801-1811.

Gupta KK, Li C, Duan A, Alberico EO, Kim OV, Alber MS, Goodson HV. 2013. Mechanism for the catastrophe-promoting activity of the microtubule destabilizer Op18/stathmin. Proc Natl Acad Sci 110: 20449-20454.

Halpin D, Kalab P, Wang J, Weis K, Heald R. 2011. Mitotic spindle assembly around RCC1-coated beads in Xenopus egg extracts. PLoS Biol 9: e1001225.

Hanley ML, Yoo TY, Sonnett M, Needleman DJ, Mitchison TJ. 2017. Chromosomal passenger complex hydrodynamics sug- 
gests chaperoning of the inactive state by nucleoplasmin/ nucleophosmin. Mol Biol Cell 28: 1444-1456.

He YJ, McCall CM, Hu J, Zeng Y, Xiong Y. 2006. DDB1 functions as a linker to recruit receptor WD40 proteins to CUL4ROC1 ubiquitin ligases. Genes Dev 20: 2949-2954.

Heald R, Tournebize R, Blank T, Sandaltzopoulos R, Becker P, Hyman A, Karsenti E. 1996. Self-organization of microtubules into bipolar spindles around artificial chromosomes in Xenopus egg extracts. Nature 382: 420-425.

Helmke KJ, Heald R. 2014. TPX2 levels modulate meiotic spindle size and architecture in Xenopus egg extracts. J Cell Biol 206: $385-393$.

Hirano T. 2016. Condensin-based chromosome organization from bacteria to vertebrates. Cell 164: 847-857.

Hirota T, Lipp JJ, Toh BH, Peters JM. 2005. Histone H3 serine 10 phosphorylation by Aurora B causes HP1 dissociation from heterochromatin. Nature 438: 1176-1180.

Honda R, Korner R, Nigg EA. 2003. Exploring the functional interactions between Aurora B, INCENP, and survivin in mitosis. Mol Biol Cell 14: 3325-3341.

Hsu JY, Sun ZW, Li X, Reuben M, Tatchell K, Bishop DK, Grushcow JM, Brame CJ, Caldwell JA, Hunt DF, et al. 2000. Mitotic phosphorylation of histone H3 is governed by Ip11/aurora kinase and Glc7/PP1 phosphatase in budding yeast and nematodes. Cell 102: 279-291.

Inoue A, Zhang Y. 2014. Nucleosome assembly is required for nuclear pore complex assembly in mouse zygotes. Nat Struct Mol Biol 21: 609-616.

Jannink G, Duplantier B, Sikorav JL. 1996. Forces on chromosomal DNA during anaphase. Biophys $J$ 71: 451-465.

Jenness C, Giunta S, Müller MM, Kimura H, Muir TW, Funabiki H. 2018. HELLS and CDCA7 comprise a bipartite nucleosome remodeling complex defective in ICF syndrome. Proc Natl Acad Sci doi: 10.1073/pnas.1717509115.

Jeyaprakash AA, Basquin C, Jayachandran U, Conti E. 2011. Structural basis for the recognition of phosphorylated histone h3 by the survivin subunit of the chromosomal passenger complex. Structure 19: 1625-1634.

Karsenti E, Newport J, Kirschner M. 1984. Respective roles of centrosomes and chromatin in the conversion of microtubule arrays from interphase to metaphase. J Cell Biol 99(1 Pt 2): $47 \mathrm{~s}-54 \mathrm{~s}$.

Kelly AE, Sampath SC, Maniar TA, Woo EM, Chait BT, Funabiki H. 2007. Chromosomal enrichment and activation of the aurora B pathway are coupled to spatially regulate spindle assembly. Dev Cell 12: 31-43.

Kelly AE, Ghenoiu C, Xue JZ, Zierhut C, Kimura H, Funabiki H. 2010. Survivin reads phosphorylated histone $\mathrm{H} 3$ threonine 3 to activate the mitotic kinase Aurora B. Science 330: 235-239.

Kinoshita K, Kobayashi TJ, Hirano T. 2015. Balancing acts of two HEAT subunits of condensin I support dynamic assembly of chromosome axes. Dev Cell 33: 94-106.

Kurat CF, Yeeles JT, Patel H, Early A, Diffley JF. 2017. Chromatin controls DNA replication origin selection, lagging-strand synthesis, and replication fork rates. Mol Cell 65: 117-130.

Lan W, Zhang X, Kline-Smith SL, Rosasco SE, Barrett-Wilt GA, Shabanowitz J, Hunt DF, Walczak CE, Stukenberg PT. 2004. Aurora B phosphorylates centromeric MCAK and regulates its localization and microtubule depolymerization activity. Curr Biol 14: 273-286.

Lens SM, Wolthuis RM, Klompmaker R, Kauw J, Agami R, Brummelkamp T, Kops G, Medema RH. 2003. Survivin is required for a sustained spindle checkpoint arrest in response to lack of tension. Embo J 22: 2934-2947.

Loomis RJ, Naoe Y, Parker JB, Savic V, Bozovsky MR, Macfarlan T, Manley JL, Chakravarti D. 2009. Chromatin binding of SRp20 and ASF/SF2 and dissociation from mitotic chromosomes is modulated by histone $\mathrm{H} 3$ serine 10 phosphorylation. Mol Cell 33: 450-461.

Lu L, Ladinsky MS, Kirchhausen T. 2011. Formation of the postmitotic nuclear envelope from extended ER cisternae precedes nuclear pore assembly. J Cell Biol 194: 425-440.
MacCallum DE, Losada A, Kobayashi R, Hirano T. 2002. ISWI remodeling complexes in Xenopus egg extracts: Identification as major chromosomal components that are regulated by INCENP-aurora B. Mol Biol Cell 13: 25-39.

Makde RD, England JR, Yennawar HP, Tan S. 2010. Structure of $\mathrm{RCC} 1$ chromatin factor bound to the nucleosome core particle. Nature 467: 562-566.

Nemergut ME, Mizzen CA, Stukenberg T, Allis CD, Macara IG. 2001. Chromatin docking and exchange activity enhancement of RCC1 by histones H2A and H2B. Science 292: 1540-1543.

Nicklas RB. 1983. Measurements of the force produced by the mitotic spindle in anaphase. J Cell Biol 97: 542-548.

Nicklay JJ, Shechter D, Chitta RK, Garcia BA, Shabanowitz J, Allis CD, Hunt DF. 2009. Analysis of histones in Xenopus laevis. II. Mass spectrometry reveals an index of cell typespecific modifications on H3 and H4. J Biol Chem 284: 10751085.

Niedzialkowska E, Wang F, Porebski PJ, Minor W, Higgins JM, Stukenberg PT. 2012. Molecular basis for phosphospecific recognition of histone $\mathrm{H} 3$ tails by Survivin paralogues at inner centromeres. Mol Biol Cell 23: 1457-1466.

Niethammer P, Bastiaens P, Karsenti E. 2004. Stathmin-tubulin interaction gradients in motile and mitotic cells. Science 303: 1862-1866.

Noujaim M, Bechstedt S, Wieczorek M, Brouhard GJ. 2014. Microtubules accelerate the kinase activity of Aurora-B by a reduction in dimensionality. PloS One 9: e86786.

Oh D, Yu CH, Needleman DJ. 2016. Spatial organization of the Ran pathway by microtubules in mitosis. Proc Natl Acad Sci 113: 8729-8734.

Ohi R, Sapra T, Howard J, Mitchison TJ. 2004. Differentiation of cytoplasmic and meiotic spindle assembly MCAK functions by Aurora B-dependent phosphorylation. Mol Biol Cell 15: 2895-2906.

Pinyol R, Scrofani J, Vernos I. 2013. The role of NEDD1 phosphorylation by Aurora A in chromosomal microtubule nucleation and spindle function. Curr Biol 23: 143-149.

Ramadan K, Bruderer R, Spiga FM, Popp O, Baur T, Gotta M, Meyer HH. 2007. Cdc48/p97 promotes reformation of the nucleus by extracting the kinase Aurora B from chromatin. Nature 450: $1258-1262$.

Rivera T, Ghenoiu C, Rodríguez-Corsino M, Mochida S, Funabiki H, Losada A. 2012. Xenopus Shugoshin 2 regulates the spindle assembly pathway mediated by the chromosomal passenger complex. EMBO J 31: 1467-1479.

Roostalu J, Cade NI, Surrey T. 2015. Complementary activities of TPX2 and chTOG constitute an efficient importin-regulated microtubule nucleation module. Nat Cell Biol 17: 1422-1434.

Sampath SC, Ohi R, Leismann O, Salic A, Pozniakovski A, Funabiki H. 2004. The chromosomal passenger complex is required for chromatin-induced microtubule stabilization and spindle assembly. Cell 118: 187-202.

Scrofani J, Sardon T, Meunier S, Vernos I. 2015. Microtubule nucleation in mitosis by a RanGTP-dependent protein complex. Curr Biol 25: 131-140.

Sessa F, Mapelli M, Ciferri C, Tarricone C, Areces LB, Schneider TR, Stukenberg PT, Musacchio A. 2005. Mechanism of Aurora $\mathrm{B}$ activation by INCENP and inhibition by hesperadin. Mol Cell 18: 379-391.

Shintomi K, Takahashi TS, Hirano T. 2015. Reconstitution of mitotic chromatids with a minimum set of purified factors. Nat Cell Biol 17: 1014-1023.

Su TT, Campbell SD, O'Farrell PH. 1999. Drosophila grapes/ CHK1 mutants are defective in cyclin proteolysis and coordination of mitotic events. Curr Biol 9: 919-922.

Tada K, Susumu H, Sakuno T, Watanabe Y. 2011. Condensin association with histone $\mathrm{H} 2 \mathrm{~A}$ shapes mitotic chromosomes. Nature 474: 477-483.

Tan L, Kapoor TM. 2011. Examining the dynamics of chromosomal passenger complex (CPC)-dependent phosphorylation during cell division. Proc Natl Acad Sci 108: 16675-16680.

Tanno Y, Kitajima TS, Honda T, Ando Y, Ishiguro K, Watanabe Y. 2010. Phosphorylation of mammalian Sgo2 by Aurora B re- 
cruits PP2A and MCAK to centromeres. Genes Dev 24: 21692179.

Tsai MY, Zheng Y. 2005. Aurora A kinase-coated beads function as microtubule-organizing centers and enhance RanGTP-induced spindle assembly. Curr Biol 15: 2156-2163.

Tseng BS, Tan L, Kapoor TM, Funabiki H. 2010. Dual detection of chromosomes and microtubules by the chromosomal passenger complex drives spindle assembly. Dev Cell 18: $903-$ 912.

Tulu US, Fagerstrom C, Ferenz NP, Wadsworth P. 2006. Molecular requirements for kinetochore-associated microtubule formation in mammalian cells. Curr Biol 16: 536-541.

Walther TC, Askjaer P, Gentzel M, Habermann A, Griffiths G, Wilm M, Mattaj IW, Hetzer M. 2003. RanGTP mediates nuclear pore complex assembly. Nature 424: 689-694.

Wang HW, Ramey VH, Westermann S, Leschziner AE, Welburn JP, Nakajima Y, Drubin DG, Barnes G, Nogales E. 2007. Architecture of the Dam1 kinetochore ring complex and implications for microtubule-driven assembly and force-coupling mechanisms. Nat Struct Mol Biol 14: 721-726.

Wang F, Dai J, Daum JR, Niedzialkowska E, Banerjee B, Stukenberg PT, Gorbsky GJ, Higgins JM. 2010. Histone H3 Thr-3 phosphorylation by Haspin positions Aurora B at centromeres in mitosis. Science 330: 231-235.

Wang E, Ballister ER, Lampson MA. 2011. Aurora B dynamics at centromeres create a diffusion-based phosphorylation gradient. J Cell Biol 194: 539-549.

Wheelock MS, Wynne DJ, Tseng BS, Funabiki H. 2017. Dual recognition of chromatin and microtubules by INCENP is important for mitotic progression. J Cell Biol 216: 925-941.

Wieczorek M, Bechstedt S, Chaaban S, Brouhard GJ. 2015. Microtubule-associated proteins control the kinetics of microtubule nucleation. Nat Cell Biol 17: 907-916.

Wilkins BJ, Rall NA, Ostwal Y, Kruitwagen T, Hiragami-Hamada K, Winkler M, Barral Y, Fischle W, Neumann H. 2014. A cascade of histone modifications induces chromatin condensation in mitosis. Science 343: 77-80.

Winkler DD, Luger K. 2011. The histone chaperone FACT: Structural insights and mechanisms for nucleosome reorganization. J Biol Chem 286: 18369-18374.

Wuhr M, Güttler T, Peshkin L, McAlister GC, Sonnett M, Ishihara K, Groen AC, Presler M, Erickson BK, Mitchison TJ, et al. 2015. The nuclear proteome of a vertebrate. Curr Biol 25: 2663-2671.

Xue JZ, Funabiki H. 2014. Nuclear assembly shaped by microtubule dynamics. Nucleus 5: 40-46.

Xue JZ, Woo EM, Postow L, Chait BT, Funabiki H. 2013. Chromatin-bound Xenopus Dppa2 shapes the nucleus by locally inhibiting microtubule assembly. Dev Cell 27: 47-59.

Yamagishi Y, Honda T, Tanno Y, Watanabe Y. 2010. Two histone marks establish the inner centromere and chromosome bi-orientation. Science 330: 239-243.

Yan J, Maresca TJ, Skoko D, Adams CD, Xiao B, Christensen MO, Heald R, Marko JF. 2007. Micromanipulation studies of chromatin fibers in Xenopus egg extracts reveal ATP-dependent chromatin assembly dynamics. Mol Biol Cell 18: 464-474.

Yokoyama H, Rybina S, Santarella-Mellwig R, Mattaj IW, Karsenti E. 2009. ISWI is a RanGTP-dependent MAP required for chromosome segregation. J Cell Biol 187: 813-829.

Yue Z, Carvalho A, Xu Z, Yuan X, Cardinale S, Ribeiro S, Lai F, Ogawa H, Gudmundsdottir E, Gassmann R, et al. 2008. Deconstructing Survivin: Comprehensive genetic analysis of Survivin function by conditional knockout in a vertebrate cell line. $J$ Cell Biol 183: 279-296.

Zhang X, Lan W, Ems-McClung SC, Stukenberg PT, Walczak CE. 2007. Aurora B phosphorylates multiple sites on mitotic centromere-associated kinesin to spatially and temporally regulate its function. Mol Biol Cell 18: 3264-3276.

Zhang MS, Arnaoutov A, Dasso M. 2014. RanBP1 governs spindle assembly by defining mitotic Ran-GTP production. Dev Cell 31: 393-404.

Zhang R, Roostalu J, Surrey T, Nogales E. 2017. Structural insight into TPX2-stimulated microtubule assembly. Elife 6: e30959.

Zierhut C, Funabiki H. 2015. Nucleosome functions in spindle assembly and nuclear envelope formation. Bioessays 37: 1074-1085.

Zierhut C, Funabiki H. 2017. The cytoplasmic DNA sensor cGAS promotes mitotic cell death. bioRxiv. doi: https://doi .org/10.1101/168070.

Zierhut C, Jenness C, Kimura H, Funabiki H. 2014. Nucleosomal regulation of chromatin composition and nuclear assembly revealed by histone depletion. Nat Struct Mol Biol 21: 617625 . 


\section{$\$_{\text {CSH }}^{\infty}$ Cold Spring Harbor Symposia SYMPOSIA on Quantitative Biology}

\section{Nucleosome-Dependent Pathways That Control Mitotic Progression}

Hironori Funabiki, Christopher Jenness and Christian Zierhut

Cold Spring Harb Symp Quant Biol 2017 82: 173-185 originally published online March 7, 2018 Access the most recent version at doi:10.1101/sqb.2017.82.034512

References This article cites 102 articles, 41 of which can be accessed free at: http://symposium.cshlp.org/content/82/173.full.html\#ref-list-1

Creative This article is distributed under the terms of the

Commons http://creativecommons.org/licenses/by-nc/4.0/, which permits reuse and License redistribution, except for commercial purposes, provided that the original author and source are credited.

Email Alerting Receive free email alerts when new articles cite this article - sign up in Service the box at the top right corner of the article or click here. 